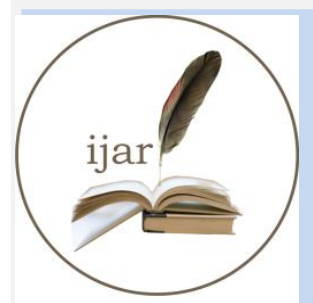

ISSN NO. 2320-5407

\section{Journal Homepage: - www.journalijar.com INTERNATIONAL JOURNAL OF ADVANCED RESEARCH (IJAR)}

Article DOI: $10.21474 / \mathrm{IJAR01/1342}$

DOI URL: http://dx.doi.org/10.21474/IJAR01/1342
INTERNATIONAL JOURNAL OF ADVANCED RESEARCH (JJAR)

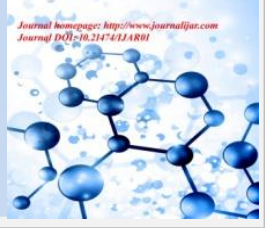

RESEARCH ARTICLE

\title{
SIGNIFICANCE OF SERUM AMYLASE AND SERUM LIPASE LEVELS IN ACUTE ORGANOPHOSPEROUS POISONING.
}

1. Junior resident.

\section{Anjay $B^{1}$, JayasinghK ${ }^{2}$, Tumbanatham $A^{3}$, Green $S^{3}$ and Ezhumalai $G^{4}$.}

2. Professor and head of the department.

3. Assistant professor.

4. Senior statistician.

\section{Manuscript Info}

Manuscript History

Received: 12 June 2016

Final Accepted: 19 July 2016

Published: August 2016

Key words:-

OP - Organophosphorous, CNS -

Central Nervous System.

\section{Abstract}

Background: Organophosphorous compounds are principally used as pesticides, and their exposure is highly prevalent in developing countries. Toxic effects of OPs are associated with significant morbidity and mortality and are a major global clinical problem. Case reports on acute pancreatitis following acute OP compound ingestion has been reported worldwide now and then, but regular studies with reference to Pancreatitis is not very much available in a serial manner. Hence an attempt was made to study pancreatic involvement through biochemical means.

Aims and objectives: To estimate serum Amylase and Lipase levels in acute organophosphorous compound poisoning, And To find out the relationship between prognosis and Hyperamylasemia and Hyperlipasemia

Methods: A total of 41 patients treated in Mahatma Gandhi Medical college hospital with organophosphorous poisoning were taken up for the study, their serum Amylase and serum Lipase levels were checked during the time of admission and during discharge with correspondence to presence of pancreatitis in patients were analysed and were treated accordingly.

Results: All the patients on our study consumed poison in a suicidal intension, the incidence were higher with the age group between 41-50 years,Female predominance was found $(61 \%)$. The most common reason for consumption in our study was found to be the familial stress (68.3\%) followed by financial stress $(24.4 \%)$. Mostly the substance in our study was mixed with water (46.3\%), followed by alcohol (29.3\%). Monocrotophos accounted for about (34.4\%) followed by chlorpyriphos (26.8\%) and methylparathion (19.5\%). Mean blood sugar - 223+128.43, mean urea $-44.98+33.58$,

Mean serum creatinine-1.40+33.582, Mean AST - 66.98+56.723,

Corresponding Author:- Anjay B

Address:- Junior resident 
Mean ALT - 65.02+62.705, Mean serum sodium 138.61+15.899, Mean serum potassium 3.72+0.864.The outcome was $12.2 \%$ death and $87.8 \%$ survival.85.3\% had normal serum amylase level; $14.6 \%$ had elevated serum amylase level which is very significant,9.8\% had significant elevation in lipase levels and was proved to have pancreatitis. 9.8\% developed pancreatitis, out of which 50\% survived and $50 \%$ died. In $22 \%$ of the total patient studied there were respiratory failure during time of presentation.

Conclusion: Serum amylase and serum lipase levels may be considered as a marker of

Organophosphorous poisoning, it enables the early recognition of severity and to identify those at risk of developing the complications. Our study shows correlation between elevated Amylase, Lipase level with respiratory failure and pancreatitis, convulsions, CNS depression, fasciculations, respiratory failure.

Copy Right, IJAR, 2016,. All rights reserved.

\section{Introduction:-}

Acute organphosphorous Poisoning (OP) still is epidemic in most parts of the world, particularly in most of the developing countries, where the toxicity of available poisons and their paucity of appropriate medical facilities ensure a very high fatality rates.

Their easy availability, lower cost compared to other poisonous substances and socio-cultural factors plays an important role in choice of OP as a self-poison and the incidence is higher in young economically active group with a common fatality rate of $20 \%$.(1) (2)

According to $\mathrm{WHO}$, worldwide estimates of pesticide poisoning number, more than 3 million each year, with which 18.2 per 100000 full time agricultural workers, 7.4 per million are school children, the reason for which would be insufficient marketing regulation, Lakh of surveillance systems, less enforcement of law, lack of training, inadequate access for information and non-existent personal protective equipment. (3)

Poisoning due to occupational exposure accounted for less than one fifth of the incidents, with a fatality rate of less than $1 \%$. More than $90 \%$ of the non-occupational incidents were suicidal, with a fatality rate more than $10 \%$ and the majority of the subjects are youngsters and farmers.

Accidental exposures accounted for $8-10 \%$ of the incidents and homicidal useless than $1 \%$ were other forms of poisoning. The reported overall mortality following OP insecticide poisoning varies from $4-30 \%$ in different countries and institutions.

In India, OP compounds (Monochrotophos, Chlorpyriphos, Methylparathion, Dimethoate, Triazhophos, Profenophos) cause more self-poisoning deaths in SouthIndia and Central India. In North India, aluminum phosphide causes most deaths with a fatality rate over $90 \%$. Other Pesticides used for self -poisoning include carbamates, Organochlorines and pyrethroids.

However efforts to decrease the period between the ingestion and initiation of treatment, restricting easy availability of organophosphorus compounds, and banning more toxic ones may prevent some suicidal deaths following organophosphorus poisoning. Organophosphorus poisoning being a very common method of suicide attempt in developing world deserves specific attention.(4)

Organophosphorous compounds are principally used as pesticides, and their exposure is highly prevalent in developing countries. Toxic effects of OPs are associated with significant morbidity and mortality and are a major global clinical problem. 
Occupational, suicidal (or) homicidal exposure to OPs produces a characteristic but treatable syndrome in humans. Thus, early recognition and timely intervention of toxicity from these compounds are of great importance, to emergency physicians and patients.

Case reports on acute pancreatitis following acute organophosphorus compound ingestion has been reported worldwide now and then, but regular studies with reference to Pancreatitis is not very much available in a serial manner. Hence an attempt was made to study pancreatic involvement through biochemical means.

Serum amylase and serum lipase being the easily available biochemical tests to screen for pancreatitis it has been selected for the study as a tool to screen and diagnose pancreatitis.

\section{Aims and Objectives:-}

1. To estimate serum Amylase and Lipase levels in acute organophosphorus compound poisoning.

2. To find out the relationship between prognosis and Hyperamylasemia and Hyperlipasemia

\section{Subjects and Methods:-}

This was a Cross sectional study, which was conducted at the Mahatma Gandhi Medical College and Research Institute Hospital, a rural tertiary care hospital with an annual volume of above 1,00,000 patients over one year period.

The Institutional Medical Ethics Committee approved this study. From January 2014 until July 2015 we enrolled patients who came with alleged history of OPC poisoning to participate in this study. Written informed consent was obtained from the first degree relatives of the patient and examination was done immediately.

We excluded all patients with the exclusion criteria and the patients who were not willing for the study and proceeded further.

\section{Brief Explanation Of The Procedure:-}

All the patients being treated in our hospital with organophosphorous poisoning were taken up for the study.

The patient/relatives were informed about the procedure and an informed consent had been obtained.

The patients who fulfilled the inclusion criteria, and willing to participate in the study, were enrolled into the study. Upon enrolment into the study, complete demographic details, relevant clinical and laboratory parameters were collected.

The details including duration of poisoning and parameters for comorbidities were collected.

The following specific data were collected through a proforma at the time of enrollment into the study:

Demography:-

Details included the following: Age, Sex, Time of Admission, Economical Status, Familial Status

Poison Particulars:-

Symptoms after consumption, immediate steps taken after OP exposure, mode of transportation

Biochemical evaluation which included:

Serum Amylase, Serum Lipase, Blood glucose, Urea, Creatinine, Liver function tests.

\section{Clinical Outcome:-}

Clinical Presentations, Pupil size, Pulse rate/min, Blood pressure

Respiratory rate/min, Secretions)

If laboratory results showed elevated levels patients were subjected for USG abdomen Serum amylase and lipase levels were repeated at the time of discharge

\section{Inclusion Criteria:-}

Patients who were undergoing treatement for Organophosphorous poison during my period of study (18months) from January 2014 to June 2015. 


\section{Exclusion criteria:-}

1. patients with additional poison intake

2. History suggestive of parotid gland disease

3. Patients with history of lipid disorders

4. Patients with history of renal or hepatic disease

5. History of intake of drugs likely to produce pancreatitis -Azathioprine, 6-Mercaptopurine, Thiazides, Frusemide

Limitations of this study:

* In this present study, patients were not subjected to CT because the study was limited to serum Amylase and lipase only.

* Autopsy study of pancreas was not done in the view of non-availability.

* Subsets of Amylase such as pancreatic and salivary Amylase was not estimated

* Due to laboratory constraints.

* Urinary Amylase was not estimated due to technical limitations.

* Serum Pseudocholinesterase levels could not be done.

\section{Observation \& results:-}

Figure 1: Shows the age distribution in our study,patients were predominantly in the age group 41-50 years occupying about 39percent of the total patients studied. The mean age group was found to be $48.20+12.738$.

Figure 2: Shows the distribution of OPC poisoning among males and females in the study and it shows males are in increased proportion when compared to females, with males occupying $61 \%$ of the total patients studied and females occupying remaining $39 \%$. The sex ratio between males and females in this study is 1.57 .

Table1: Shows us the following parameters in our study population. Mean Blood Urea being 44.98+33.582,Mean Serum Creatinine 1.40+33.582, Mean Blood Sugar being 223+128.438, Mean AST66.98+56.723, Mean ALT 65.02+62.705, Mean Serum Sodium 138.61+15.899, Mean Serum Potassium 3.72+0.864

Figure 1: Shows the description of reason for poisoning, which reveals predominantly familial $68 \%$ of the total patients studied, followed by financial $25 \%$ of the total population studied and others $7 \%$ of the total population studied.

Table 3:Reveals the mode of consumption of the OPC poison, in which the most being mixed with water $46 \%$ of the total population studied, followed by alcohol $29 \%$ of the total population studied, followed by milk $15 \%$ of the total population studied and direct consumption being $10 \%$ of the total population studied.

Figure 4: Reveals the agents of the OPC poison used by patients in our study, in which the most being Monocrotophos 34\% $46 \%$ of the total population studied, followed by Chlorpyriphos $27 \%$ of the total population studied, followed by Methylparation 20\% of the total population studied and Dimethoate 10\%, Profenophos 5\% and Triazophos $2 \%$ of the total population studied.

Table 4: Sows respiratory failure in the patients immediately at the time of presentation, which happened in $22 \%$ of the total patient studied.

Table 5: Explains the incidence of fasciculations present during the time of arraival. Around 15\% of the patients had fasciculations during time of presentation.

Figure 5: Tells us the percentage of patients who had developed convulsion as a complication due to OP poisoning, $5 \%$ of patients developed convulsions.

Table 6: Shows outcome of the OPC poisoning patients among which $12.2 \%$ died and $87.8 \%$ survived in our study.

Table 7:This figure shows the OPC poisoning patients who developed Pancratitis. 9.8\% of the patients developed pancreatitis, remaining had a normal pancreas.

Figure 6: As an incidental finding we got about $17 \%$ patients with Hypernatremia and $17 \%$ patients with Hyponatremia. Out of those who sustained Hypernatremia about 2 patients died $(\mathbf{2 8 . 5 7 \%})$.

Table 8: The above table shows details of the patient's amylase levels during admission, which showed that 91.2\% of the patients survived had a normal serum amylase levels and $71.4 \%$ of patients with elevated serum amylase also survived, also 28.6\% of patients with elevated Serum Amylase died.

Table 9: Shows details of the patient's Lipase levels during admission, which showed that $91.9 \%$ of the patients survived had a normal serum lipase levels and $50 \%$ of patients with elevated serum lipase also survived, also $50 \%$ of patients with elevated Serum Lipase died.

Table 10: Shows the admission serum amylase mean as well as discharge values, it also says about lipase mean during admission as well as discharge Levene's Test for Equality of Variances was applied and which 
showed significance in the Admission lipase levels and discharge lipase levels. The amylase values are not statistically significant.

Table 11: Shows the pupil size and the outcome, out of which, $91.7 \%$ patients who survived had a normal pupil size and $8.3 \%$ of people with normal sized pupil died. Among the patients who had constricted pupils 86.2\% survived and $13.8 \%$ died.

Table 12: Shows outcome with pancreatitis, which showed a 50\% survival among the affected patients.

\section{Discussion:-}

Organophosphates and Carbamates are potentially and frequently used pesticides which very often produce lifethreatening poisoning. There are more than 50,000 organophosphorous compounds synthesized since the first one by Clermont in 1857. All these compounds have the mechanism of action: Irreversible inactivation of acetylcholinesterase (ACh). The clinical symptoms varies from the classic cholinergic syndrome to flaccid paralysis and intractable seizures. Nearly $99 \%$ of fatal poisoning occurs mostly in developing countries, particularly among farmers. Till today, Atropine and Oxime continues to be the prime position in the specific management of OP poisoning.

Because of its easy availability, it is not surprising that the use of OP compounds in suicide attempts has mushroomed from a disturbing early trend to being the commonest modes of suicidal poisoning which accounted for $100 \%$ in our study. This rate was consistent with the findings of MahadiBalali Mood et al. (5) whereas it was reported to be $67 \%$ by AM Saadeh et al (6). There was no incidence suggestive of accidental exposure in our study. This incidence of suicidal attempts, may be mostly because of the uncontrolled sale and use of these agents as pesticides by the farmers all over the country.

Age, Gender Prevalence:-

The vast majority of poisonings followed oral ingestion of liquid form and almost for all the patients gastric lavage was immediately done on receiving the patient in casualty. The incidence was higher (39\%) in the age group of 4150 followed by $(24.4 \%)$ in the age group of 31-40. These were well correlated with previous studies done by Ahmed SM et all.(6)

The most common reason for consumption in our study was found to be the familial stress $(68.3 \%)$ followed by financial stress $(24.4 \%)$.

Mostly the substance in our study was mixed with water (46.3\%) followed by alcohol (29.3\%).Monocrotophos accounted for about (34.4\%) of poisoning followed by Chlorpyriphos (26.8\%) and Methylparathion (19.5\%)

\section{Clinical symptoms:-}

The accumulation of ACh in nerve terminals, results in continued stimulation with subsequent paralysis of receptors and accounts for the clinical signs of muscarinic, nicotinic and CNS effects. Both the present study, and the study by Mahdi Balali-Mood et al. (5) found association between the severity of poisoning and clinical manifestations. The most marked muscarinic signs in our study population were,miosis (34.14\%) with mean pupil size of 0.95 , excessive secretions $(53.65 \%)$, and respiratory distress $(25 \%)$. The most prominent of the nicotinic effect is muscular end plate block, resulting in muscle weakness and fasciculations.

\section{Biochemical evaluation:-}

The biochemical parameters results have not shown much variation.

Mean blood sugar of patients were 223, mean blood urea were 44.98 and serum Creatnine 1.40

It was incidentally noted that $19.5 \%$ of patients had hypernatremia.

Remaining parameters were within normal limits in most of the patients in our study, which was also indicated by MahdiBalali-Mood et al. (5)

\section{Respiratory Depression:-}

The most troublesome complication of OP poisoning was respiratory depression which could be due to reasons such as: aspiration of gastric contents, excessive secretions, pneumonia and septicemia complicating adult respiratory distress syndrome. Of the 41 patients in our study, respiratory depression was observed in 9 (22\%) cases. Early 
recognition of respiratory failure, prompt endotracheal intubations and mechanical ventilation are life-saving in severe OP poisoning.

\section{Serum Amylase and serum Lipase levels in OP poisoning:-}

OP insecticides increase the intraductal pressure and exocrine pancreatic flow. The increase in pressure leads to extravasation of pancreatic fluid. This increased pancreatic exocrine flow could be due to direct cholinergic hyperstimulation of pancreatic acinar and ductal cells. In the study, the Amylase levels were significantly elevated at the time of admission[117.07 U/L] and have shown a gradual remission with proper treatment and during discharge the levels decreased to $[52.20 \mathrm{U} / \mathrm{L}]$, which was significantly $(\mathrm{P}$ value $=0.002)$ higher. A paired $\mathrm{T}$ test was applied and found that it was statistically significant. It was concluded that there is a significant reduction of 64.878 in mean Amylase levels.

Lipase levels were at the time of admission $[53.85 \mathrm{U} / \mathrm{L}]$ and have shown a gradual remission with proper treatment and during discharge the levels decreased to $[27.34 \mathrm{U} / \mathrm{L}]$, which was significantly $(\mathrm{P}$ value $=0.008)$ higher. A paired $\mathrm{t}$ test was applied and found that it was statistically significant. It was concluded that there is a significant reduction of 26.512 in mean Lipase levels.

Evidence of pancreatitis where found in 4 patients $(9.8 \%)$ and out of which 2patients died (4.8\%).

From our observation, it can be suggested that estimation of Amylase levels would be extremely useful to assess the clinical severity. Age and sex of the patients have no significant relationship with the amylase levels. In our study, there was no significant correlation between elevated Amylase and Lipase levels and the outcome. From the observation we made, it could be suggested that OP pesticide poisoning is a serious condition that needs rapid diagnosis and prompt treatment.

\section{Conclusion:-}

In India, Organophosphorous compounds cause more suicidal deaths among the earning and nonearning members of the society. Of the 41 patients in our study 35 patients (85.3\%) had normal serum amylase level; 6 patients (14.6\%) had elevated serum amylase level which is very significant, also 4 patients $(9.7 \%)$ had significant elevation in lipase levels and were proved to have pancreatitis.

From the observation we made, it could be suggested that OP pesticide poisoning is a serious condition that needs rapid diagnosis and treatment. The mean Amylase level in first 24 hours of OP poisoning was $154 \mathrm{U} / \mathrm{L}$ which is significantly higher than the control groups.

There is a Female predominance in our study.

Middle age group 41-50 years are the commonly encountered in poisoning by organophosphorous compounds.

The severity of the clinical manifestation and mortality have no association with age.

Monocrotophos and Parathion has been highly lethal compounds.

Reason for poisoning being predominantly familial followed by financial.

The bad bedside prognostic factors which correlated very well with serum

Amylase and serum lipase levels in the order of increasing severity include

i) Convulsions (Amylase -355U/L, Lipase-124U/L)

ii) Severe secretions (Amylase -155U/L, Lipase- 64U/L)

iii) Respiratory failure (Amylase - 200U/L, Lipase- 87U/L)

iv)Pancreatitis (Amylase - 456U/L, Lipase- 235.25U/L)

Hence Serum amylase and serum lipase levels may be considered as a marker of Organophosphorous poisoning, since it enables the early recognition of severity and also helps to identify those at risk of developing the complications of Organophosphorous poisoning. Our study also showed that there was a significant correlation between markedly elevated Amylase, Lipase level and respiratory failure and therefore poor outcome.

A significant rise in Serum Amylase \& Lipase level also portends various complications that include convulsions, CNS depression, fasciculations and respiratory failure.

However, as the study was limited to a small population due to financial and laboratory constraints, analysis of a larger group would definitely give an insight into the further finer relationship between serum amylase level and clinical severity and outcome in OP poisoning. 
Tables And Figures

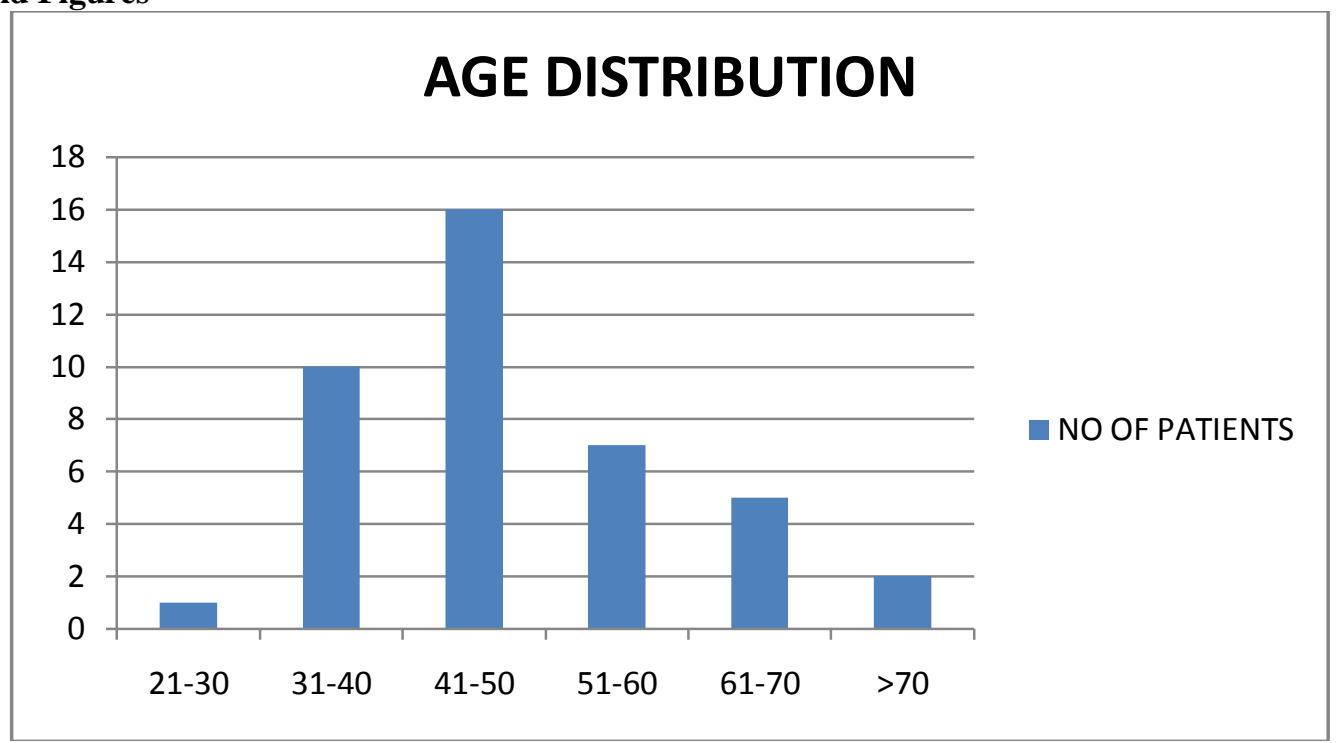

Figure 2:- Age distribution in our study

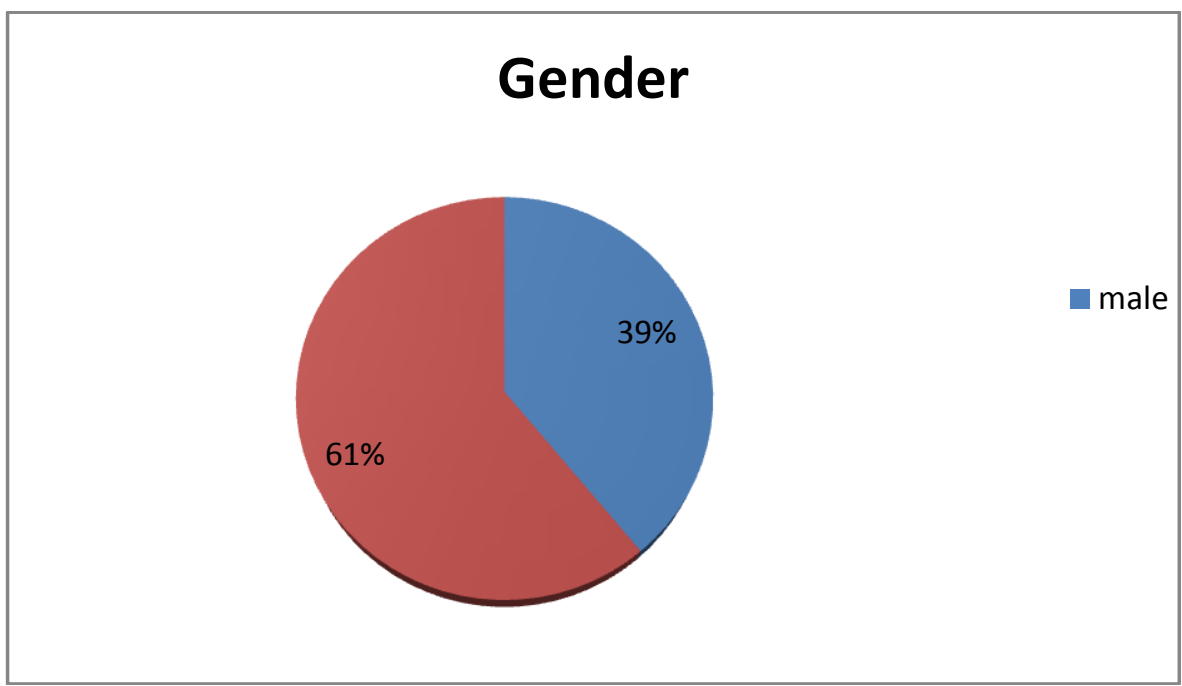

Figure 3:- Gender distribution of our study

Table 1:- Biochemical parametes and other parameters

\begin{tabular}{|l|l|l|}
\hline PARAMETERS & MEAN & STANDERD DEVIATION \\
\hline BLOOD SUGAR & 223 & 128.438 \\
\hline BLOOD UREA & 44.98 & 33.582 \\
\hline SERUM CREATNINE & 1.40 & 1.180 \\
\hline AST & 66.98 & 56.723 \\
\hline ALT & 65.02 & 62.705 \\
\hline AMLASE (admission) & 117.07 & 144.434 \\
\hline AMYLASE (discharge) & 52.20 & 48.518 \\
\hline SERUM SODIUM & 138.61 & 15.899 \\
\hline SERUM POTASSIUM & 3.72 & 0.864 \\
\hline SERUM LIPASE (admission) & 53.85 & 63.747 \\
\hline SERUM LIPASE (discharge) & 27.34 & 3.275 \\
\hline AGE & 48.20 & 12.7348 .208 \\
\hline PUPILS & 0.95 & 0.8047 \\
\hline
\end{tabular}




\section{Reason for consumption}

a familial $\quad$ financial $\square$ others

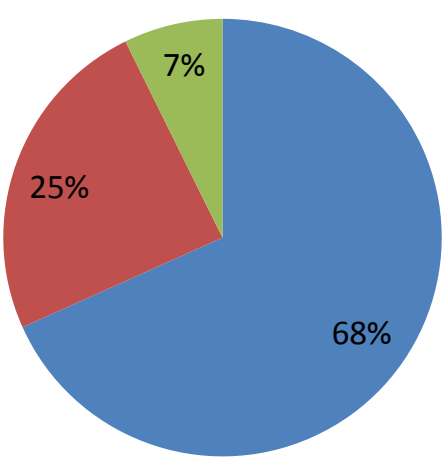

Figure 4:- Description of reason for poisoing

Table 2:- Mode of consumption

\begin{tabular}{|l|l|l|}
\hline & Frequency & Percentage \\
\hline Water & 19 & 46.3 \\
\hline Milk & 6 & 14.6 \\
\hline Alcohol & 12 & 29.3 \\
\hline Direct & 4 & 9.8 \\
\hline
\end{tabular}

Table 3:- Respiratory Failure

\begin{tabular}{|l|l|l|}
\hline & Frequency & Percent \\
\hline Absent & 32 & 78.0 \\
\hline Present & 9 & 22.0 \\
\hline
\end{tabular}

Table 4:- Incidence of Fasciculations

\begin{tabular}{|l|l|l|}
\hline Fasciculations & No Of patients & Percentage \\
\hline Present & 6 & 15 \\
\hline Absent & 35 & 85 \\
\hline
\end{tabular}

Table 5:- Outcome in our study

\begin{tabular}{|l|l|l|}
\hline OUTCOME & NO OF PATIENTS & PERCENTAGE (\%) \\
\hline ALIVE & 36 & 87.8 \\
\hline DEAD & 5 & 12.2 \\
\hline
\end{tabular}

\begin{tabular}{|l|l|l|}
\hline PANCREATITIS & NO OF PATIENTS & PERCENTAGE(\%) \\
\hline Absent & 37 & 90.2 \\
\hline Present & 4 & 9.8 \\
\hline
\end{tabular}

Table 7:- Correlation between Amylase levels in living and dead individuals

\begin{tabular}{|l|l|l|l|l|}
\hline $\begin{array}{l}\text { Amylase at } \\
\text { admission }\end{array}$ & Living & Death & X2 & P value \\
\hline Normal & $91.2 \%$ & $8.8 \%$ & 2.114 & 0.146 \\
\hline Abnormal & $71.4 \%$ & $28.6 \%$ & & \\
\hline
\end{tabular}




\section{Agents used}

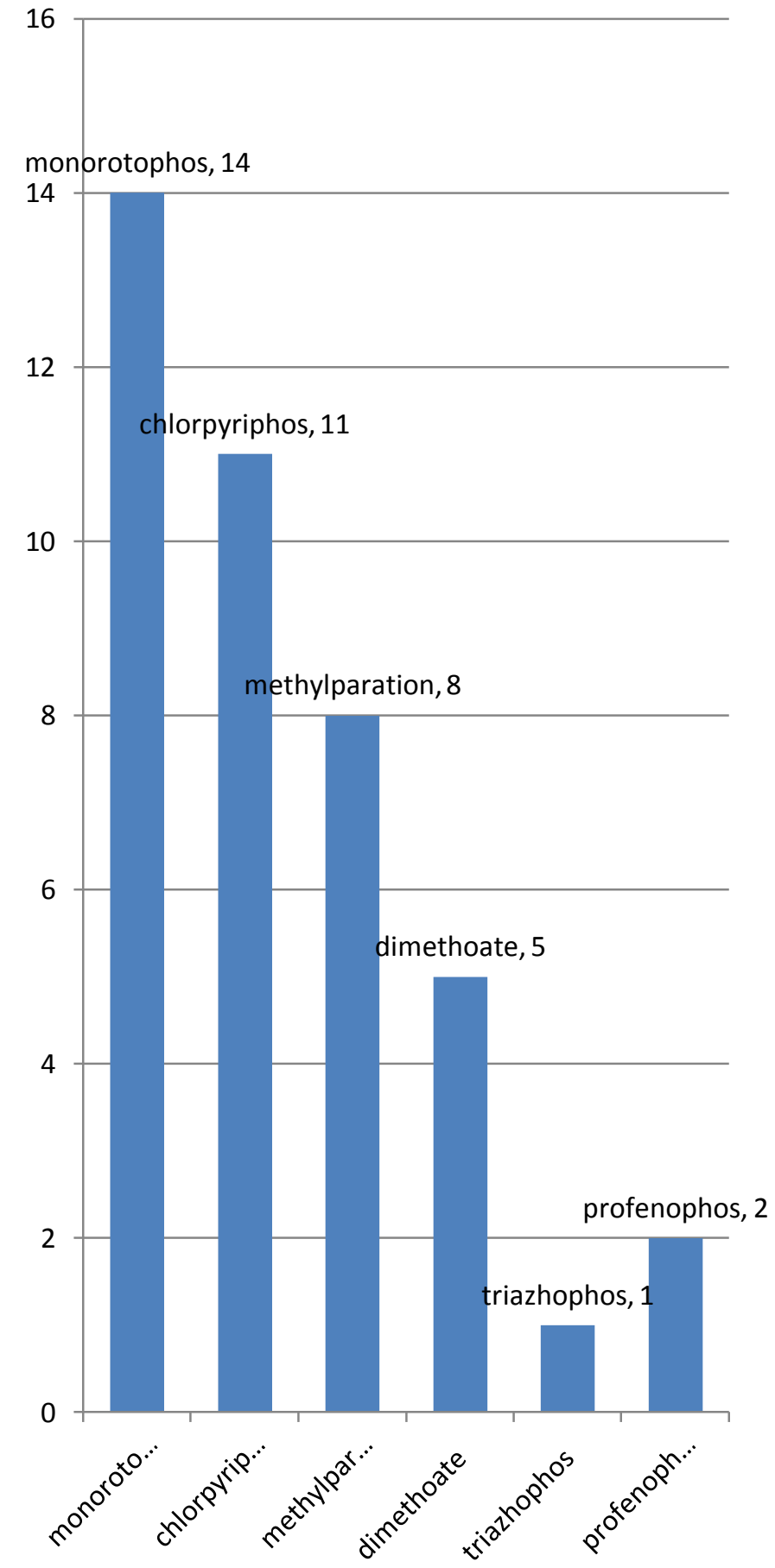

Figure 5:- compound used 


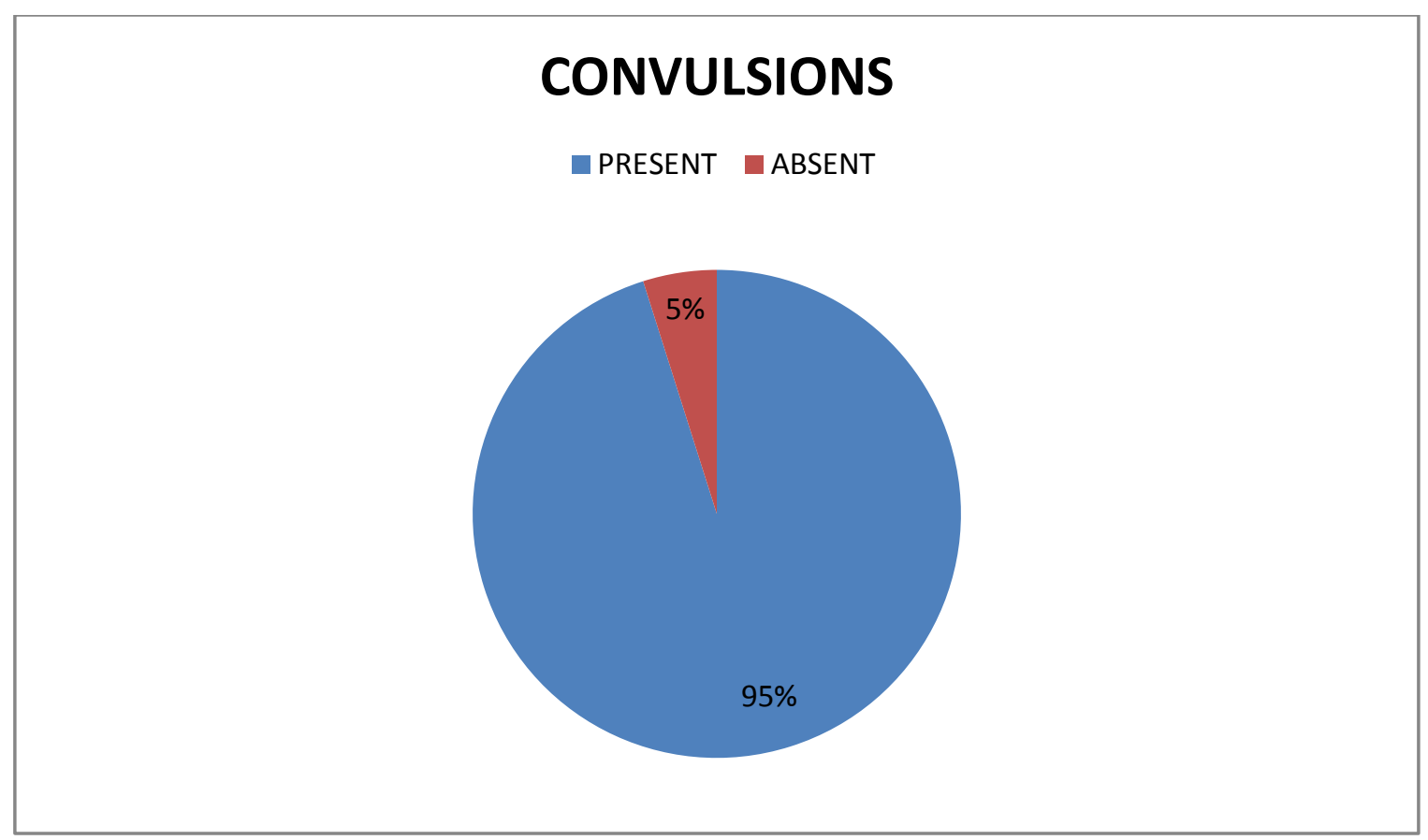

Figure 6:- incidence of convulsions in our study

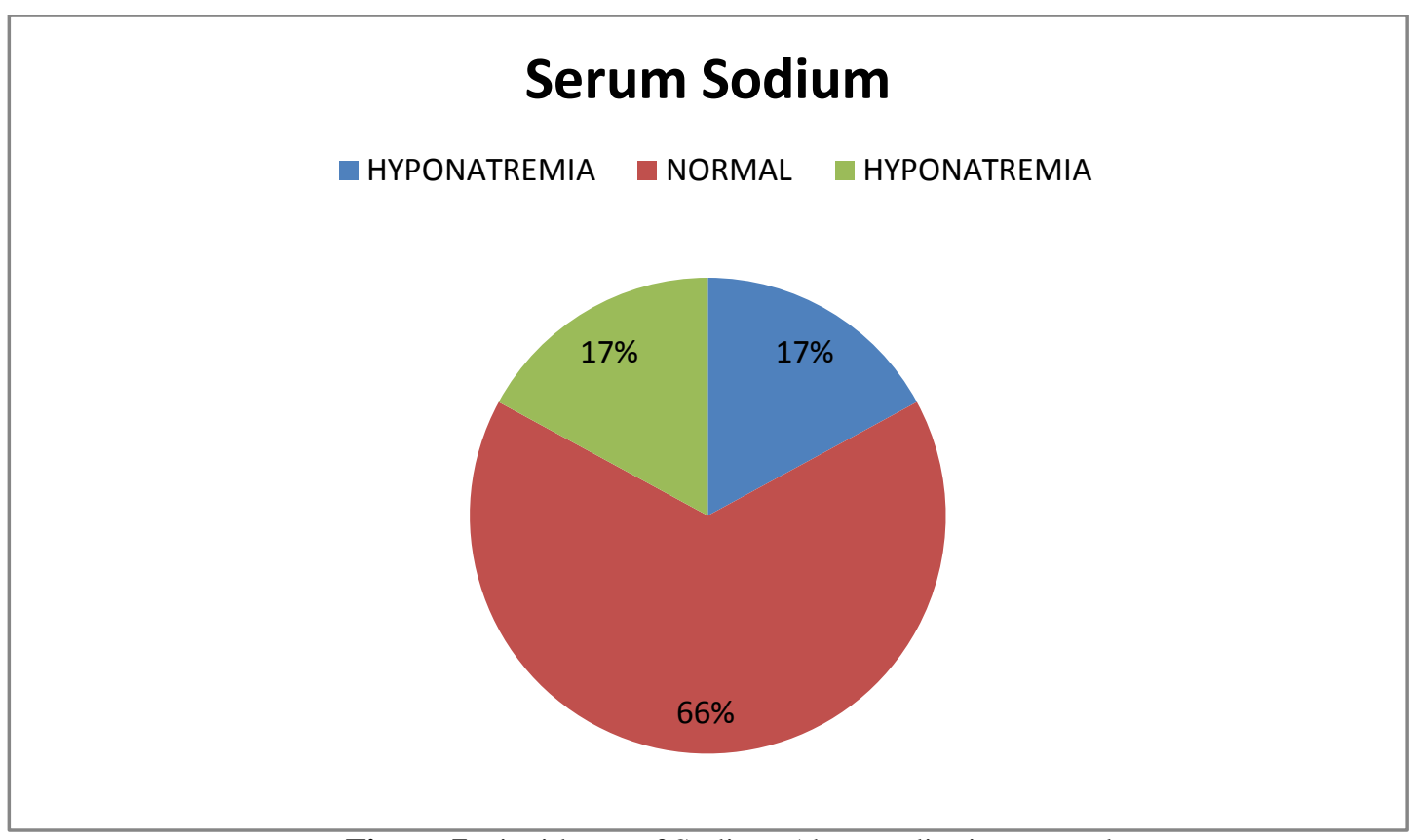

Figure 7:- incidence of Sodium Abnormality in our study

Table 8:- Correlation between Lipase in living and dead

\begin{tabular}{|l|l|l|l|l|}
\hline Lipase at admission & Living & Death & X2 & P value \\
\hline Normal & $91.9 \%$ & $8.1 \%$ & 0.15 & 0.066 \\
\hline Abnormal & $50 \%$ & $50 \%$ & & \\
\hline
\end{tabular}


Table 9:- Comparison between amylase and lipase in admission and discharge

\begin{tabular}{|l|l|l|l|l|l|l|l|l|}
\hline \multicolumn{3}{|l}{} & F & Sig & t & \multicolumn{2}{l|}{ Significance } & $\begin{array}{l}\text { Mean } \\
\text { difference }\end{array}$ \\
\hline $\begin{array}{l}\text { Admission } \\
\text { Amylase }\end{array}$ & $111.19+140.629$ & $159.40+181.709$ & 1.418 & 0.241 & -695 & .491 & NS & -48. \\
\hline $\begin{array}{l}\text { Admission } \\
\text { Lipase }\end{array}$ & $45.75+43.957$ & $112.20+137.418$ & 23.358 & .000 & -1.07 & .027 & S & -66.450 \\
\hline $\begin{array}{l}\text { Discharge } \\
\text { Amylase }\end{array}$ & $59.44+47.402$ & 0 & 2.844 & .1 & 2.774 & 0.008 & S & 59.444 \\
\hline $\begin{array}{l}\text { Discharge } \\
\text { Lipase }\end{array}$ & $31.14+19.519$ & 0 & 4.179 & .048 & 3.529 & 0.001 & S & 31.139 \\
\hline
\end{tabular}

Table 10: comparison between pupil size with outcome

\begin{tabular}{|l|l|l|}
\hline Pupil size & Living & Death \\
\hline Normal & $91.7 \%$ & $8.3 \%$ \\
\hline Constricted & $86.2 \%$ & $13.8 \%$ \\
\hline
\end{tabular}

Table 12: Comparison between pancreatitis with outcome

\begin{tabular}{|l|l|l|l|l|}
\hline Pancreatitis & Living & Percentage & Death & Percentage \\
\hline Present & 2 & $50 \%$ & 2 & $50 \%$ \\
\hline Absent & 34 & $91.89 \%$ & 3 & $8.1 \%$ \\
\hline
\end{tabular}

\section{Reference:-}

1. M. Eddlestron, L. Szinicz, P.Eyer. Oximes in acute organophosphorous pesticidepoisoning : a systematic review of clinical trials. QJ Med.J. $2002 ; 275-283$.

2. Bull D. A growing problem: pesticides and the third world poor, oxford: Oxfam 1982

3. WHO | Acute pesticide poisoning: a proposed classification tool [Internet]. WHO. [cited2015 Aug 9]. Available from: http://www.who.int/bulletin/volumes/86/3/07-041814/en/

4. Kar N. Lethality of suicidal organophosphorus poisoning in an Indian population: exploring preventability. Ann Gen Psychiatry. 2006 Nov 21;5:17.

5. Lee WC. The clinical significance of hyperamylasemia in organophosphate poisoning. J ToxicolClin 1998;36(7):73-81.

6. A.M. Saadeh, N.A. Farsakh, M.K. Al. Ali. Cardiacmanifestations of acutecarbonate and organophosphate poisoning. Heart 1997; 77: 461-464. 